\title{
The short-term effects of energy drinks on near visual performance
}

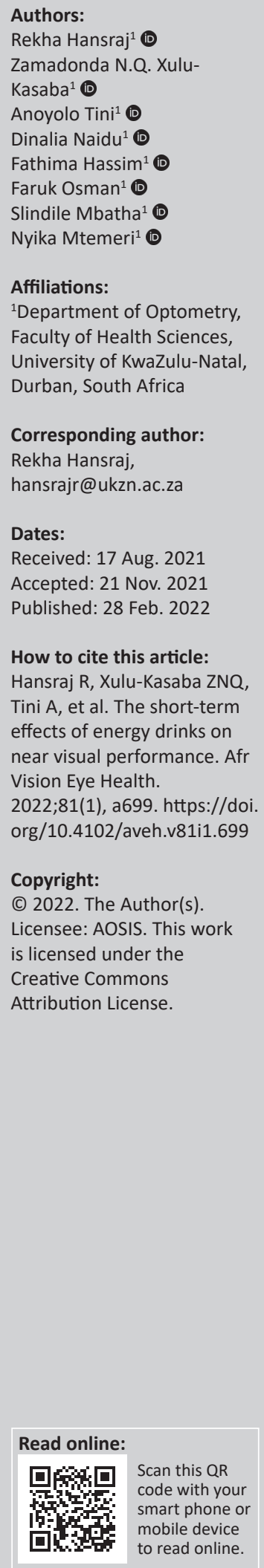

Background: Energy drinks have gained popularity amongst young adults in recent years. Widespread effects of its main ingredient caffeine have been observed on the nervous system; however, little is known about the effects of these drinks on the visual system.

Aim: This research study investigated the effects of a chosen energy drink on near vision and near contrast sensitivity.

Setting: The data were collected at a university optometry clinic in south eastern South Africa.

Methods: A single-blinded, crossover study was conducted on 56 healthy subjects aged 18-30 years. Subjects were randomised, such that they consumed either the energy drink reboost or water (control) on separate days. Near visual acuity was measured using a near Logarithm of the Minimum Angle of Resolution (LogMAR) chart and contrast sensitivity using the MARS contrast sensitivity test. Near visual acuity and contrast sensitivity measurements were taken at baseline and again at $30 \mathrm{~min}, 60 \mathrm{~min}$ and $90 \mathrm{~min}$ intervals, following consumption. Data were analysed using repeated measures analysis of variance (ANOVA) and univariate analysis.

Results: Both near visual acuity and contrast sensitivity, post-energy drink consumption, showed a marginal increase over the testing period. Near visual acuity increased from -0.13 LogMAR at baseline to $-0.17 \log M A R$ at $90 \mathrm{~min}$. Contrast sensitivity increased from $1.77 \log$ units at $30 \mathrm{~min}$ to $1.78 \mathrm{log}$ units at $90 \mathrm{~min}$ similar to that observed with the control. In both cases; however, the changes were neither statistically $(p>0.05)$ nor clinically significant.

Conclusion: The energy drink reboost had no short-term effect on near vision performance as measured with near visual acuity and contrast sensitivity.

Keywords: energy drinks; near vision performance; near visual acuity; contrast sensitivity; caffeine.

\section{Introduction}

Energy drinks have become increasingly popular over the years with the global sales having reached 57.4 billion dollars in the year 2020. ${ }^{1}$ Even though the first energy drink was introduced in 1949, they only became popular in 1997 with the introduction of Red Bull. ${ }^{2,3}$ By 2006, there were more than 500 varieties creating a multibillion dollar industry for manufacturers and distributors, ${ }^{3}$ with South Africa showing the third highest increase in sales for the years 2013-2014. ${ }^{4}$ Energy drinks were initially marketed to athletes as 'energy boosters'; however, the focus of marketing strategies has more recently shifted to adolescents and young adults, the majority of whom are males aged 13-35 years. ${ }^{5}$ Energy drink consumption, on a weekly basis, has also been found to be associated with the male gender, smoking, alcohol consumption and being overweight. ${ }^{6,7}$ These beverages contain caffeine in combination with small amounts of taurine, B vitamins, guarana, ginseng, sucrose, glucuronolactone and inositol. ${ }^{8}$

Caffeine is the main constituent in energy drinks, and therefore, remains the most widely studied energy drink ingredient. ${ }^{9}$ Most energy drinks have a caffeine content of $50 \mathrm{mg}-550 \mathrm{mg}$ per can and/or bottle depending on the brand. ${ }^{2}$ Glade, ${ }^{10}$ following a detailed literature review of the beneficial effects of caffeine on human physiological systems, reported that caffeine decreases fatigue, enhances physical and cognitive performance, increases alertness, decreases mental fatigue and enhances short-term memory. These may be some reasons for its popularity particularly with young adults and anecdotally more particularly at stressful times such as during examinations. Research, however, has also shown many potential adverse effects resulting from the consumption of large amounts of caffeine. Excessive caffeine consumption has been linked to acute and chronic headaches caused by hyper excitability of cortical cells, ${ }^{11}$ as well as irregular 
heartbeat, kidney failure and heart attacks. ${ }^{12}$ Of note is that many of the adverse effects have been observed in children and adolescents. ${ }^{13}$

As a result of the increased awareness of the widespread effects of caffeine on the nervous system, studies have been conducted to assess the ocular and visual changes associated with caffeine intake. Caffeine enhances autonomic innervation to the intrinsic muscles of the eye. ${ }^{14}$ It stimulates the sympathetic nervous system, thereby affecting the iris, ciliary and eyelid musculature, as well as the lacrimal gland, choroidal and conjunctival vessels. ${ }^{14}$ However, it is also known to affect accommodation, which is controlled by the parasympathetic nervous system. These paradoxical effects suggest an overall enhancement of the autonomic nervous system. ${ }^{14}$

In addition, the ocular effects of caffeine intake include changes in the structural properties of the visual cortex and increased perceptual instability ${ }_{1}^{15}$ increase in tear secretion in non-dry eye subjects, ${ }^{16}$ paradoxical changes in intraocular pressure ${ }^{17,18}$ and changes in macular perfusion. ${ }^{19}$ All of these aspects can have an influence on vision when performing near tasks.

Particular attention has been given to the amplitude of accommodation and pupil size following the consumption of caffeine, with many studies reporting resultant increases in both the amplitude of accommodation ${ }^{14,20}$ and pupil dilation. ${ }^{14,21}$ The increase in the amplitude of accommodation is as a result of caffeine binding to the adenosine receptors. ${ }^{22}$ This releases acetylcholine that stimulates the muscarinic receptors of the ciliary body causing its contraction. ${ }^{22}$ An increase in the amplitude of accommodation may be expected to improve reading performance; however, Kirshner and Schmid $^{23}$ had reported a negative correlation between caffeine intake and reading improvement. Furthermore, this increase in amplitude means a closer working distance, which may not be ideal when working with devices such as laptops and just advantageous with other smaller hand-held electronic devices.

Caffeine also inhibits the actions of adenosine leading to a rise in neurotransmitters, such as epinephrine and activation of the sympathetic nervous system causing pupil dilation, which brings about an increase in spherical aberration and retinal illumination changes. ${ }^{24}$ Additives, such as guarana, further increase the caffeine content of energy drinks, ${ }^{12}$ and there are also large amounts of various sugars present in energy drinks, which can lead to increased plasma glucose concentrations ${ }^{25}$ and visual changes. Subsequently, Abokyi et al. ${ }^{14}$ identified the need for further studies on vision itself, highlighting that pupil size and accommodation are not the only determinants in retinal image formation. Moreover, previous studies have focused on ocular and visual function changes with minimal attention to visual performance.

Considering the high usage of energy drinks amongst young adults, especially college students, ${ }^{26}$ it is important to be aware of any negative influences on their visual function and subsequently learning capabilities. Visual acuity (VA) can be used as an indicator of vision performance but is limited in its assessment of quality of vision, which can be determined by contrast sensitivity testing. Contrast sensitivity is the ability to distinguish an object from its background with minimal contrast. ${ }^{27}$ Decreased contrast sensitivity may result in eye muscles becoming easily fatigued. Energy drinks may provide an instant solution to temporary difficulties; however, any possible negative effects it has on near vision performance remains unknown.

\section{Materials and methods}

A cross-over, single-blinded, experimental design was used in this study with all subjects being assessed with both the energy drink and the placebo. The study setting was a university-based optometry clinic.

Convenience sampling was used to select 56 subjects. Individuals aged 18-30 years, of all races and both genders, who could achieve 6/6 aided Snellen distance VA and 6/6 reduced Snellen equivalent, were considered for inclusion in the study sample. Excluded from the study were those with systemic or ocular diseases, users of any systemic or ocular medication, individuals with a tear break-up time of less than $10 \mathrm{~s}$ and Schirmer's test result of less than $10 \mathrm{~mm}$ in $5 \mathrm{~min}$, pupil size of less than $2 \mathrm{~mm}$ under photopic conditions, those with accommodation anomalies, and all who had a history of three or more caffeine drinks in a week.

The energy drink reboost was chosen for this study based on anecdotal evidence that it was the most common energy drink purchased by students at the chosen university. Subjects were instructed to abstain from drinking caffeine or energy drinks for a full week prior to clinical testing as a wash out period. Water, whilst not ideal, was chosen as a placebo as it contains no ergogenic ingredients, including sugar, as those found in energy drinks.

Data collection for each subject took place over two occasions, which were one week apart, at minimum. Subjects were randomly distributed into two groups that determined which of them would receive the energy drink on the first occasion. Baseline measurements for near VA and contrast sensitivity were taken using a Logarithm of the Minimum Angle of Resolution (LogMAR) chart and the MARS contrast sensitivity chart at $40 \mathrm{~cm}$, respectively. Subjects were then given either $250 \mathrm{~mL}$ of the energy drink or water, which they were required to consume within $5 \mathrm{~min}$. A timer was set after complete consumption of the $250 \mathrm{~mL}$, and each subject was tested at $30 \mathrm{~min}$ intervals over a period of $90 \mathrm{~min}$. The testing of near VA and contrast sensitivity was randomised at each interval with an average of three readings being taken. All testing was carried out on the subject's dominant eye, which was pre-determined prior to taking the baseline measurements using the hole in the card method. In between the testing intervals, subjects watched a video projected $3 \mathrm{~m}$ away to minimise any near visual stimulation. Subjects were required to empty their bladders just before the clinical 
testing commenced and encouraged to only urinate after the $90 \mathrm{~min}$ period, if possible.

Two researchers measured the near VA and near contrast sensitivity, respectively. This allowed for standardisation of instructions and recordings. Both examiners were masked as to which drink the subject had been exposed to on each occasion and only unmasked at the end of the data collection phase. Separate rooms were used for these measurements, but they were performed under identical lighting conditions. Data were captured and analysed using the Statistical Package for Social Sciences (SPSS version 25) under the guidance of a statistician. Descriptive statistics, as well as the paired $t$-test and analysis of variance (ANOVA) analysis, were used to test for differences between the experimental and control data at a $95 \%$ level of confidence, that is, $p<0.05$.

\section{Ethical considerations}

The study received ethical clearance from the relevant institutional Biomedical Research and Ethics Committee (BE142/19) and the tenets of the Declaration of Helsinki were adhered to. All subjects completed informed consent forms prior to participation in the study.

\section{Results}

A total of 56 healthy subjects (36 females and 20 males), with a mean age of $20.52 \pm 2.30$ years (range: $17-28$ years) and mean body mass index (BMI) of $23.71 \mathrm{~kg} / \mathrm{m}^{2} \pm 4.80 \mathrm{~kg} /$ $\mathrm{m}^{2}$ participated in this study. The sample included 36 African people, 18 Indian people and two white people. A total of 39 subjects were right eye dominant and 17 left eye dominant. The photopic pupil sizes ranged between $3.8 \mathrm{~mm}$ and $7.00 \mathrm{~mm}$ with a mean of $5.61 \mathrm{~mm}$. Subjects had a mean tear break up time (TBUT) of $6.64 \mathrm{~s} \pm 1.57 \mathrm{~s}$ and the results for the Schirmer 2 of $16.61 \mathrm{~mm} \pm 4.09 \mathrm{~mm}$.

Figure 1 shows the time courses of mean near VA at baseline and at $30 \mathrm{~min}, 60 \mathrm{~min}$ and $90 \mathrm{~min}$ intervals post-treatment for both the energy drink and water. The numerical mean visual acuities at each time interval are shown in the table under the plot.

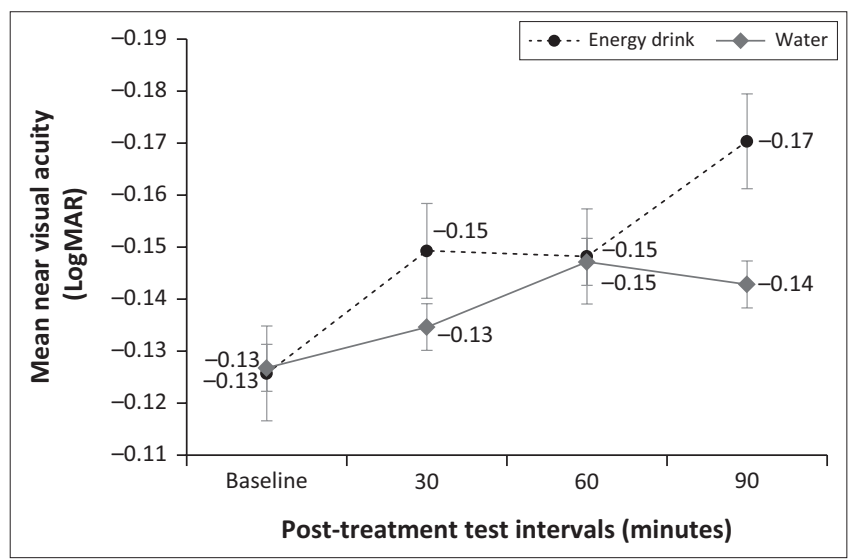

FIGURE 1: Time courses of mean near visual acuity at baseline and at $30 \mathrm{~min}$, $60 \mathrm{~min}$ and $90 \mathrm{~min}$ post-treatment with $250 \mathrm{~mL}$ energy drink or water.
Following ingestion of the energy drink, the mean near VA increased from $-0.13 \log$ MAR at baseline to $-0.15 \log$ MAR at $30 \mathrm{~min}$, thereafter staying constant at $60 \mathrm{~min}$ and further increasing to $-0.17 \log$ MAR at $90 \mathrm{~min}$. The change from baseline was less with the control (water) remaining constant at $-0.13 \log$ MAR from baseline to $30 \mathrm{~min}$, thereafter increasing to $-0.15 \log$ MAR at $60 \mathrm{~min}$ and lastly decreasing to $-0.14 \log$ MAR at $90 \mathrm{~min}$. In comparison, therefore, the energy drink was observed to have increased the mean near VA slightly more than the control over the 90 min time period with an increase of one letter read at $30 \mathrm{~min}$ and two letters read at $90 \mathrm{~min}$. Repeated measures ANOVA analysis found the difference between the baseline, energy drink and control to be statistically significant only at the 90 min interval at a $95 \%$ level of confidence $(p=0.009)$. As a difference of $0.1 \log$ MAR units reflects a one line difference in near VA, the change in near VA with the energy drink was not found to be clinically significant compared with baseline or to the control, at any testing interval.

Multiple analysis regression found no influence of age, BMI or TBUT on the change in near VA at a $95 \%$ level of confidence (Table 1). There was no influence on gender on changes in near VA ( $t$-test, $p>0.05)$.

Figure 2 shows time courses of mean contrast sensitivity at baseline and at $30 \mathrm{~min}, 60 \mathrm{~min}$ and $90 \mathrm{~min}$ intervals posttreatment for both the energy drink and water. The numerical mean contrast sensitivity values at each time interval are shown in the table under the plot.

The mean contrast sensitivity following the ingestion of the energy drink was observed to increase from $1.75 \mathrm{log}$ units at baseline to $1.77 \mathrm{log}$ units at $30 \mathrm{~min}$, further increasing to $1.78 \mathrm{log}$ units at $60 \mathrm{~min}$ and thereafter staying constant at $90 \mathrm{~min}$. Contrast sensitivity with the control was observed to have increased from $1.75 \log$ units

TABLE 1: Multiple regression analysis: Body mass index, age and tear break up time versus change in near visual acuity post-treatment.

\begin{tabular}{|c|c|c|c|c|}
\hline \multirow[t]{2}{*}{ Model } & $\begin{array}{l}\text { Unstandardised } \\
\text { coefficients }\end{array}$ & \multirow{2}{*}{$\begin{array}{c}\text { Standardised } \\
\text { coefficients: } \\
\text { Beta }\end{array}$} & \multirow[t]{2}{*}{$t$} & \multirow[t]{2}{*}{ Significance } \\
\hline & $\begin{array}{c}\text { Standard } \\
\text { error }\end{array}$ & & & \\
\hline
\end{tabular}

\begin{tabular}{lcccrl}
\hline \multicolumn{6}{l}{ Change in near VA 30 min post-treatment } \\
Constant & 0.003 & 0.098 & - & 0.035 & 0.972 \\
BMI & 0.001 & 0.002 & 0.107 & 0.753 & 0.455 \\
Age & -0.002 & 0.004 & -0.096 & -0.632 & 0.530 \\
Tear break up & 0.001 & 0.005 & 0.017 & 0.116 & 0.908 \\
time in seconds & & & & & \\
Change in near VA 60 min post-treatment & & & \\
Constant & 0.230 & 0.139 & - & 1.652 & 0.105 \\
BMI & -0.001 & 0.002 & -0.076 & -0.550 & 0.584 \\
Age & -0.009 & 0.005 & -0.249 & -1.688 & 0.098 \\
Tear break up & -0.002 & 0.008 & -0.041 & -0.293 & 0.771 \\
time in seconds & & & & & \\
Change in near VA 90 min post-treatment & & & \\
Constant & 0.110 & 0.108 & - & 1.020 & 0.312 \\
BMI & 0.001 & 0.002 & 0.061 & 0.436 & 0.664 \\
Age & -0.007 & 0.004 & -0.248 & -1.670 & 0.101 \\
Tear break up & 0.002 & 0.006 & 0.056 & 0.404 & 0.688 \\
time in seconds & & & & & \\
\hline
\end{tabular}

$\mathrm{VA}$, visual acuity; BMI, body mass index. 


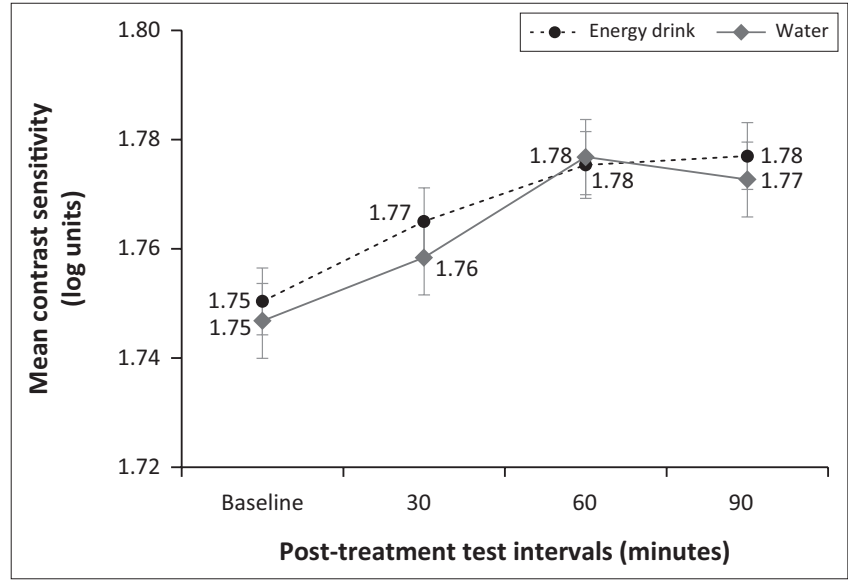

FIGURE 2: Time courses of contrast sensitivity at baseline and at $30 \mathrm{~min}, 60 \mathrm{~min}$ and 90 min post-treatment with $250 \mathrm{~mL}$ energy drink or water.

TABLE 2: Multiple regression analysis: Body mass index, age and tear break up time versus change in near contrast sensitivity post-treatment.

\begin{tabular}{|c|c|c|c|c|c|}
\hline \multirow[t]{2}{*}{ Model } & \multicolumn{2}{|c|}{$\begin{array}{l}\text { Unstandardised } \\
\text { coefficients }\end{array}$} & \multirow{2}{*}{$\begin{array}{c}\text { Standardised } \\
\text { coefficients: } \\
\text { Beta }\end{array}$} & \multirow[t]{2}{*}{$t$} & \multirow[t]{2}{*}{ Significance } \\
\hline & $B$ & $\begin{array}{l}\text { Standard } \\
\text { error }\end{array}$ & & & \\
\hline \multicolumn{6}{|c|}{ Change in CS 30 min post-treatment } \\
\hline Constant & -0.147 & 0.083 & - & -1.779 & 0.081 \\
\hline BMI & 0.000 & 0.001 & 0.044 & 0.323 & 0.748 \\
\hline Age & 0.004 & 0.003 & 0.167 & 1.153 & 0.254 \\
\hline $\begin{array}{l}\text { Tear break up } \\
\text { time in seconds }\end{array}$ & 0.001 & 0.004 & 0.044 & 0.326 & 0.746 \\
\hline \multicolumn{6}{|c|}{ Change in CS 60 min post-treatment } \\
\hline Constant & -0.293 & 0.089 & - & -3.291 & 0.002 \\
\hline BMI & 0.002 & 0.002 & 0.128 & 1.006 & 0.319 \\
\hline Age & 0.011 & 0.003 & 0.430 & 3.178 & 0.003 \\
\hline $\begin{array}{l}\text { Tear break up } \\
\text { time in seconds }\end{array}$ & -0.002 & 0.005 & -0.046 & -0.362 & 0.719 \\
\hline \multicolumn{6}{|c|}{ Change in CS 90 min post-treatment } \\
\hline Constant & -0.277 & 0.098 & - & -2.835 & 0.007 \\
\hline BMI & 0.002 & 0.002 & 0.141 & 1.092 & 0.280 \\
\hline Age & 0.010 & 0.004 & 0.359 & 2.611 & 0.012 \\
\hline $\begin{array}{l}\text { Tear break up } \\
\text { time in seconds }\end{array}$ & -0.004 & 0.005 & -0.096 & -0.739 & 0.464 \\
\hline
\end{tabular}

$\mathrm{BMI}$, body mass index; $\mathrm{CS}$, contrast sensitivity.

at baseline to $1.76 \log$ units at $30 \mathrm{~min}$, thereafter increasing to $1.78 \log$ units at $60 \mathrm{~min}$, before decreasing to $1.77 \mathrm{log}$ units at $90 \mathrm{~min}$. In comparison, therefore, the energy drink was observed to have increased contrast sensitivity more than the control over the $90 \mathrm{~min}$ time period when compared with baseline, however the differences were not found to be statistically significant at any interval with the repeated measure ANOVA analysis. The differences were also not clinically significant as a difference of $0.08 \mathrm{log}$ units would have reflected a two-letter difference in contrast sensitivity.

Multiple analysis regression found no influence of BMI or TBUT on the change in near contrast sensitivity $(p>0.05)$ (Table 2), other than for age at only the $60 \mathrm{~min}$ and $90 \mathrm{~min}$ post-treatment interval.

\section{Discussion}

There is a high usage of energy drinks amongst young adults, especially college students. ${ }^{24}$ It was considered of particular importance to assess the effect of energy drinks on near visual performance, which could influence their learning as students often consume energy drinks, particularly during study and examination periods. Whilst VA is often used as an indicator of vision performance, it is limited in its assessment of quality of vision, which can be better determined by contrast sensitivity testing. Hence, this study included both these clinical tests to assess near visual performance. This study observed no statistically or clinically significant change in both near VA and contrast sensitivity following ingestion of the energy drink in comparison with the control, which had no ergogenic substances compared with those found in the former. Furthermore, any change in near VA or contrast sensitivity was not associated with age, gender or body weight, with the exception of older age and a greater change in contrast sensitivity at the latter two post-treatment intervals. It is known that contrast sensitivity declines linearly from the age of 20 years $^{28}$, which together with the expected pupil dilation as established in other studies ${ }^{14,21}$ could account partly for this observation. No previous studies on these aspects are available for any further comparison.

A change may have been expected in both these parameters because of previous findings of an increase in pupil size following caffeine intake, ${ }_{1}^{14,21,29}$ which was expected to influence vision because of an associated increase in spherical and higher order abberations. ${ }^{21}$ However, this study found neither statistically nor clinically significant changes. As both tasks in this study were at a near working distance any pupil dilation may have been negated because of the near triad involving pupil constriction when viewing an object at near..$^{30,31}$ Furthermore, previous studies ${ }^{14,32}$ have reported a significant increase in the amplitude of accommodation and accommodative response following caffeine intake, which would also stimulate pupillary constriction. Bardak et al. ${ }^{21}$ asserted that pupil dilation is not significant in healthy young adults who are not chronic caffeine consumers as was the case in this study. This may also explain why no significant change in contrast sensitivity was observed in this study as one of the factors that influence contrast sensitivity is retinal luminance, which would not have been altered if the pupil size did not change significantly. However, an improvement in vision may have been expected as an increase in amplitude of accommodation following caffeine intake from parasympathetic stimulation may have corrected any accommodative errors and subsequently improved retinal quality and VA. ${ }^{30}$ However, it was not found in this study.

Despite no significant change being found, a trend was observed of a marginal improvement in near VA and contrast sensitivity with both the energy drink and water. Whilst this is contrary to the negative correlation between caffeine intake and reading improvement reported by Kirschner \& Schmid ${ }^{23}$ a statistically significant difference in near VA between the energy drink and water was observed at the 90 min interval, which is supported by the findings of an improvement in reading ability on reduction of caffeine intake. ${ }^{23}$ 
Interestingly, the marginal improvement from baseline was observed in near VA and contrast sensitivity at all testing intervals for both the energy drink and water, which was supposed to have served as a control. This may have been related to tear film dynamics. In this regard, Osei et al. ${ }^{16}$ reported a marginal increase in Schirmer 1 following water intake and an increased tear secretion at $45 \mathrm{~min}$ and $90 \mathrm{~min}$ following caffeine intake. Increased tear secretion may, therefore, have been responsible for the marginal improvement and the statistically significant increase in VA at the 90 min interval observed in this study as the tear film has been proven to affect optical quality. ${ }^{33,34}$ In addition, this study observed no association between tear function and the change in either near vision or contrast sensitivity following consumption of the energy drink.

This study had some limitations. It was difficult to find a placebo that was similar to the energy drink in terms of taste and appearance but without ergogenic effects. During data collection, which was performed at varying times of the day, there was poor dietary control in terms of what participants ate or drank prior to their assessment. In addition, compliance with the washout period could not be assured. The findings of this study are limited to the age and BMI group studied. Future studies should include the measurement of pupil sizes and tear function assessments at the testing intervals.

\section{Conclusion}

Despite the paradoxical effects on the autonomic system found in previous studies and the negative impact expected on vision overall, this study found that the chosen energy drink had no effect on near vision performance as measured with near VA and contrast sensitivity in young adults.

\section{Acknowledgements Competing interests}

The authors declare that they have no financial or personal relationships that may have inappropriately influenced them in writing this article.

\section{Authors' contributions}

All authors, other than N.M. were involved in the conceptualisation of this study, data collection and the compilation of the research article. N.M. provided guidance on the design and statistical analysis.

\section{Funding information}

This research work received no specific grant from any funding agency in the public, commercial or not-for-profit sectors.

\section{Data availability}

The data that support the findings of this study are available from the corresponding author, R.H., upon reasonable request.

\section{Disclaimer}

The views and opinions expressed in this article are those of the authors and do not necessarily reflect the official policy or position of any affiliated agency of the authors.

\section{References}

1. Fontinelle A. The energy drinks industry [serial online]. Investopedia; 2021 [cited 2021 June 20]. Available from: https://www.investopedia.com/articles/investing/ 022315/energy-drinks-industry.asp

2. Reissig CJ, Strain EC, Griffiths RR. Caffeinated energy drinks - A growing problem. Drug Alcohol Depend. 2009;99:1-10. https://doi.org/10.1016/j.drugalcdep.2008.08.001

3. Boyle M, Castillo VD. Monster on the loose. Fortune. 2006;154:116-122.

4. Red Bull Website [document on the Internet]. 2019 [cited 2019 Jan 15]. Available from: http://energydrink-pl.redbull.com/firma-red-bull

5. Bailey RL, Saldanha LG, Gahche JJ, Dwyer JT. Estimating caffeine intake from energy drinks and energy supplements in the United States. Nutr Rev. 2014;72(S1):9-13. https://doi.org/10.1111/nure.12138

6. Dillon P, Kelpin S, Kendler K, Thacker L, Dick D, Svikis D. Gender differences in anysource caffeine and energy drink use and associated adverse health behaviors. Caffeine Adenosine Res. 2019;9(1):12-19. https://doi.org/10.1089/caff.2018.0008

7. Friis $\mathrm{K}$, Lyng $\mathrm{Jl}$, Lasgaard $\mathrm{M}$, Larsen $\mathrm{FB}$. Energy drink consumption and the relation to socio-demographic factors and health behaviour among young adults in Denmark. A population-based study. Eur J Public Health. 2014;24(5):840-844. https://doi.org/10.1093/eurpub/cku003

8. Duchan E, Patel ND, Feucht C. Energy drinks: A review of use and safety for athletes. Phys Sportsmed. 2010;38(2):171-179. https://doi.org/10.3810/psm.2010.06.1796

9. Lohi JJ, Huttunen KH, Lahtinen TM, Kilpeläinen AA, Muhli AA, Leiono TK. Effect of caffeine on simulator flight performance in sleep-deprived military pilot students. Mil Med. 2007;172(9):982-987. https://doi.org/10.7205/MILMED.172.9.982

10. Glade MJ. Caffeine - Not just a stimulant. Nutr J. 2010;26(10):932-938. https:// doi.org/10.1016/j.nut.2010.08.004

11. Espinosa Jovel CA, Sobrino Mejía FE. Caffeine and headache: Specific remarks. Neurologia 2017;32(6):394-398. https://doi.org/10.1016/j.nrl.2014.12.016

12. Seifert SM, Schaechter JL, Hershorin ER, Lipshultz SE. Health effects of energy drinks on children, adolescents, and young Adults. Pediatrics. 2011;127(3):511528. https://doi.org/10.1542/peds.2009-3592

13. Alsunni AA. Energy drink consumption: Beneficial and adverse health effects. Int Health Sci. 2015;9(4):468-474. https://doi.org/10.12816/0031237

14. Abokyi S, Owusu-Mensah J, Osei KA. Caffeine intake is associated with pupil dilation and enhanced accommodation. Eye. 2017;31:615-619. https://doi org/10.1038/eye.2016.288

15. Coren $\mathrm{S}$. The effect of caffeine ingestion on the perceived instability of visual patterns. Int J Psychophysiol. 2002;43(2):185-189. https://doi.org/10.1016/ S0167-8760(01)00151-9

16. Osei K, Ovenseri-Ogbomo G, Kyei S, Ntodie M. The effect of caffeine on tear secretion. Optom Vis Sci. 2013;91(2):171-177. https://doi.org/10.1097/OPX.0000000000000129

17. Jiwani $A$, Rhee $D$, Brauner $S$, et al. Effects of caffeinated coffee consumption on intraocular pressure, ocular perfusion pressure and ocular pulse amplitude: $A$ intraocular pressure, ocular perfusion pressure and ocular pulse amplitude: A
randomized controlled trial. Eye. 2012;26:1122-1130. https://doi.org/10.1038/ eye.2012.113

18. Ebeigbe JA, Obahiagbon EA. Acute effects of consumption of energy drink on intraocular pressure and blood pressure-pilot study. Afr J Med Health Sci. 2013;12(1):20-24. https://doi.org/10.4103/2384-5589.129918

19. Okuno T, Sugiyama T, Tominaga M, Kojima S, Ikeda T. Effects of caffeine on microcirculation of the human ocular fundus. Jpn J Ophthalmol. 2002;46:170-176. https://doi.org/10.1016/S0021-5155(01)00498-1

20. Zhai $H$, Goss DA, Hammond RW. The effect of caffeine on the accommodative response/accommodative stimulus function and on the response $\mathrm{AC} / \mathrm{A}$ ratio. Curr Eye Res. 1993;12(6):489-499. https://doi.org/10.3109/02713689309001827

21. Bardak H, Gunay M, Mumcu U, Bardak Y. Effect of single administration of coffee on pupil size and ocular wavefront aberration measurements in healthy subjects. Biomed Res Int. 2016;2016:9578308. https://doi.org/10.1155/2016/9578308

22. Kardon R. Anatomy and physiology of the autonomic nervous system. In: Miller NR, Newman NJ, Biousse V, Kerrison JB, editors. Walsh and Hoyt Clinical NeuroOphthalmology. 6th ed. Baltimore, MD: Williams \& Wilkins, 2005; p. 649-714.

23. Kirshner AJ, Schmid R. The effects of caffeine on near point plus acceptance. J Am Optom Assoc. 1984;55(2):97-102.

24. Alfonso JF, Fernández-Vega L, Baamonde MB, Montés-Micó R. Correlation of pupil size with visual acuity and contrast sensitivity after implantation of an apodized diffractive intraocular lens. J Cataract Refract Surg. 2007;33(3):430-438. https:// doi.org/10.1016/j.jcrs.2006.10.051

25. Shearer J, Reimer RA, Hittel DS, Gault MA, Vogel HJ, Klein MS. Caffeine-containing energy shots cause acute impaired glucoregulation in adolescents. Nutrients. 2020;12(12):1-14. https://doi.org/10.3390/nu12123850

26. Malinauskas BM, Aeby VG, Overton RF, Carpenter-Aeby T, Barber-Heidal K. A survey of energy drink consumption patterns among college students. Nutr J. 2007;6:35. https://doi.org/10.1186/1475-2891-6-35 
27. Jindra LF, Zemon V. Contrast sensitivity testing: A more complete assessment of vision. J Cataract Refract Surg. 1989;15(2):141-148. https://doi.org/10.1016/ S0886-3350(89)80002-1

28. Gillespie-Gallery H, Konstantakopoulou E, Harlow JA, Barbur JL. Capturing agerelated changes in functional contrast sensitivity with decreasing light levels in monocular and binocular vision. Invest Ophthalmol Vis Sci. 2013;54:6093-6103. https://doi.org/10.1167/iovs.13-12119

29. Ajayi OB, Ukwade MT. Caffeine and intraocular pressure in a Nigerian population. J Glaucoma. 2001:10:25-31. https://doi.org/10.1097/00061198-200102000-00006

30. Lotfi K, Grunwald JE. The effect of caffeine on the human macular circulation. Investig Ophthalmol Vis Sci. 1991;32(12):3028-3032.
31. Shanti V, Manjree D. Comparison of the effect of caffeine containing energy drink and Glucon D on auditory and visual reaction time. Int I Med Res Health Sci. 2016;5(7):94-100.

32. López-Gil N, Iglesias I, Artal P. Retinal image quality in the human eye as a function of the accommodation. Vision Res. 1998;38(19):2897-2907. https://doi. org/10.1016/S0042-6989(98)00086-8

33. Radhakrishnan $\mathrm{H}$, Charman WN. Age-related changes in ocular aberrations with accommodation. J Vis. 2007;7(7):11, 1-21. https://doi.org/10.1167/7.7.11

34. Albarrán C, Pons AM, Lorente A, Montés R, Artigas JM. Influence of the tear film on optical quality of the eye. Cont Lens Anterior Eye. 1997;20(4):129-135. https:// doi.org/10.1016/S1367-0484(97)80011-2 